\title{
El CID Y DIYenís: ¿HÉROES DE NOVELA O DE EPOPEYA?
}

\author{
Miguel Castillo Didier \\ Universidad de Chile, Chile.
}

Resumen: El hecho de que de la historia de Diyenís Akritas se hayan editado primero las versiones arcaizantes, a partir del MS de Trebizonda, en 1875, y de que la primera traducción al inglés haya sido hecha del MS de Grottaferrata, en 1956, ha tenido por resultado el que repetidamente se haya calificado de «novela» al poema. La publicación por el profesor Stilianós Alexíu de la edición crítica del MS del Escorial, en 1985, ha abierto el camino para su estudio como texto más cercano a una epopeya popular. Los cuestionamientos al carácter épico del Diyenís $E$ han sido semejantes a los que ha habido respecto del epicismo del Poema del Cid. Aquí, como parte de un trabajo más extenso, se examinan las características que en una y otra obra demuestran su carácter heroico. Así, tanto el Cid como Diyenís deben considerarse héroes de una epopeya y no de una novela.

Palabras Claves: Cid, Diyenís Akritas, epopeya, novela.

Abstract: The archaizing versions of the history of Digenis Acritas (from the MS of Trebizond) were the first to be edited, in 1875, and the first translation was made from the MS of Grottaferrata, in 1956. Both facts resulted in the poem being called a "novel". After Stilianos Alexiu published in 1985 his critical edition of the MS of El Escorial, the close relation of the text to a popular epic could for the first time be studied. The doubts concerning the epic character of the Digenis $E$ have been similar to those which were set forth concerning the Poema de Mio Cid. The epic features of both poems are analyzed here as part of a longer research in which both the Cid and Digenis are considered heroes of an epic, not a novel.

Key words: Cid, Digenis Acritas, epic, novel.

Recibido 15.07.08 - Aceptado 2.09.08

Email: micastilgriego@gmail.com Fono 2392292. Director del Centro de Estudios Griegos Bizantinos y Neohelénicos de la Universidad de Chile. Miembro de la Academia Chilena de la Lengua. Dirección postal: San Francisco 1141. Santiago de Chile 
$\mathrm{M}$ ucho interés presenta el estudio comparado del Poema del Cid con la Epopeya de Diyenís Akritas. A partir de la publicación de la edición crítica del Manuscrito Escorial del poema griego, realizada por el profesor Stilianós Alexíu, y publicada en $1988^{1}$, se ha tenido acceso a la "versión" sin duda más cercana al poema popular sobre el famoso héroe medieval griego, o de los poemas que en algún momento fueron reunidos para formar un texto de cierto sentido biográfico de la legendaria figura del guerrero. No son pocos los aspectos en que estos poemas están cerca uno del otro ${ }^{2}$ y en que ambos se alejan de la Chanson de Roland, de los Nibelungos y del Beowulf.

El más importante punto de proximidad de las dos obras nos parece, sin duda, la semejanza del escenario histórico en que ocurren los hechos narrados, y a ello debemos agregar la coincidencia del tiempo en que surgieron las epopeyas. El Cid cumple sus hazañas en el siglo XI, cuando todavía casi la mitad de España estaba en poder del Islam. En Bizancio, en el siglo $\mathrm{X}$, los cristianos habían logrado reconquistar ciertas regiones perdidas dos siglos antes. Los poemas aparecen en el siglo XII, según las cronologías trazadas por Menéndez Pidal y Alexíu. Colin Smith ha postulado una fecha posterior a 1140 para el Poema del Cid, pero en todo caso, si se acepta su tesis, el poema sería fechado a comienzos del siglo XIII ${ }^{3}$.

Y en ambos «frentes» de la confrontación habían transcurrido ya tres siglos de combates. Las primeras conquistas árabes de territorios griegos comienzan casi enseguida de la muerte de Mahoma en el siglo VII y varias décadas después, a principios de la centuria siguiente, el año 711, empieza el rápido avance de los árabes en la Península Ibérica.

Los cantares que llegaron a conformar la Epopeya de Diyenís surgieron en la frontera entre el mundo cristiano y el musulmán, en Oriente, y el Poema de Mío Cid y otros poemas épicos en España surgieron en el clima de la frontera entre esos dos mundo, en Occidente. En ese ambiente fronterizo se dan confrontaciones armadas y períodos de paz; hostilidad y convivencia;

${ }^{1}$ Publicada por la Editorial Hermís, en Atenas, junto a los Cantares de Armuris y de El hijo de Andrónico. Ver bibliografía.

${ }^{2}$ Esbozos de aproximación a este paralelo se han publicado: Praktiká tou IV Sinedríou Singritikís Logotejnías, Atenas 1995; y Estudios Neogriegos en españa e Iberoamérica, Actas del I Congreso de Neohelenistas de Iberoamérica, AthosPérgamos, Universidad de Granada, Granada 1997.

${ }^{3}$ C. Smith: «Introducción» a Poema de Mío Cid, edición de Colin Smith, 17a. ed. , Madrid, Cátedra 1991, 29. 
intolerancia y tolerancia; matrimonios mixtos y amistades mixtas; captura de botines y conquistas de tierras que más tarde a veces se negocian; tomas de prisioneros y embajadas de rescate e intercambios; separación de familias por raptos o aprisionamiento de algunos de sus integrantes; luchas enconadas y reconciliaciones; largas desapariciones y reconocimientos entre parientes después de años. Y se desarrolla un espíritu heroico para el cual el honor, el valor, la intrepidez, la fortaleza, el apropiamiento de tierras, y el prestigio que todo ello otorga, constituyen valores fundamentales. Testimonio de los hechos característicos de la frontera y del contacto, lucha y convivencia entre los dos pueblos de credos distintos, hay tanto en la épica hispánica como en la poesía heroica griega medieval. Recordemos que el Cid tiene un amigo fiel, a toda prueba, en el moro Abengalvón; y que Mudarra, el vengador de los Infantes de Lara, es un mestizo. Y en el campo fronterizo oriental, bizantino, Diyenís, él mismo es mestizo, hijo de cristiana y de un emir árabe; y que el hijo del héroe Armuris se casará con la hija del emir que había apresado a su padre, y así se sellará la reconciliación y la paz.

El principal héroe castellano y el más recordado héroe griego, cuyos nombres han asociado no sólo autores helenos sino también estudiosos extranjeros como Krumbacher y Vasiliev, son claramente «hijos» de aquel mundo fronterizo.

Parece paradojal preguntarse si estos personajes son héroes de novela o de epopeya. El porqué de tal pregunta está en los cuestionamientos que se han formulado en torno al carácter de los poemas de los cuales aquellos son protagonistas. ¿Predomina en esas obras el elemento novelesco sobre el épico?

En el caso del Poema de Diyenís, podríamos decir que el cuestionamiento de su carácter épico posee dos raíces. Una tiene que ver con las circunstancias en que se llegó a conocer, fuera del ámbito griego el "tema" de Diyenís. En efecto, la traducción inglesa del manuscrito de Grottaferrata realizada por John Mavrogordatos, y el estudio preliminar que la acompañó, publicados en 1956, tuvieron una muy amplia difusión y constituyeron durante varias décadas la única fuente de acercamiento al "tema". Esto contribuyó, sin duda, a formar una opinión sobre ese texto, el de Grottaferrata, el cual no representa la forma original del poema, ni una forma próxima a la original, sino una refundición erudita en la que los elementos novelescos son muy claros. No es raro, entonces, que la calificación que Mavrogordatos hizo del poema como "novela" o "poema novelesco" se haya generalizado entre quienes se referían al tema de Diyenís, basándose en la única fuente asequible. 
Cuatro episodios novelescos encontramos en G "agregados" a la historia del Diyenís que nos presenta el manuscrito Escorial: el encuentro del héroe con un emperador bizantino, no nombrado; el relato sobre una doncella, la hija de Aploravdis, rescatada y luego seducida por Diyenís; la muerte de la amazona Maximú a manos del héroe; y la muerte de los padres de Diyenís. Pero, además, gran cantidad de detalles amplían y modifican hechos relatados y objetos mencionados o descritos brevemente en E. Como G, en general las refundiciones eruditas amplían el carácter breve y sobrio de narraciones y descripciones del E, desfigurándolas. Así, por ejemplo, las versiones de Andros-Atenas y las de Oxford y Pasjalis, introducen una especie de prólogo o introducción al Canto del emir, padre de Diyenís, extenso relato sobre la joven que será la madre del héroe, con predicciones de adivinos acerca de su destino y de la manera de evitarlo. Jeffreys ha denominado ""prólogo astrológico" a esta sección.

Curiosamente, Valero, quien tradujo la versión $\mathrm{G}$ al español ${ }^{4}$ y trabajó sobre ella, no dudó del carácter épico de Diyenís, a propósito de la cuestión de la "epicidad": "Por lo que se refiere a los rasgos épicos, si entendemos la epopeya tal como la define Lesky, es preciso admitir que en el Diyenís se encuentran casi todos los elementos para considerarlo como tal. En efecto, el héroe está en el centro de la obra y sus cualidades esenciales son el valor y la fuerza. Su forma de actuar viene determinada por el honor y concurren en él otros elementos característicos, como la amistad, la lucha, las cacerías, los grandes banquetes y las canciones" . Hay que observar de paso que no todas las connotaciones a que alude Valero sea dan en el héroe como lo presenta el E. Luego de insistir en el carácter épico del personaje, este autor utiliza el término "novela épica", aunque "cargando más las tintas en el adjetivo". Escribe que "creado el héroe como símbolo de paz y convivencia", "el poeta es consciente de que un héroe sin hazañas no es tal héroe. Ahora bien, no puede crear un héroe sanguinario, pues no simbolizaría la paz; de ahí que le haga realizar hazañas a veces fantásticas, como la del dragón, a veces contra "gentes fuera de la ley", los apelates, en las que el Akritas, solitario y caballeroso, humano y sobrehumano, puede hacer alarde de sus excepcionales cualidades, sin que, al tiempo, empañe la gran misión para la que fue ideado [...]. Tal es la clave histórica y tal su reflejo y su dualista tratamiento en la

\footnotetext{
4 Vasilios Diyenís Akritas, Ed. Bosch, Barcelona 1985, con una amplia «Introducción". Ver bibliografía.

5 J. Valero, op. c.it., 57.
} 
obra literaria mitad épica y mitad novelesca o, si se quiere, "novela épica", cargando más las tintas en el adjetivo que en el sustantivo"

También es curioso comprobar que al salir a la luz en 1875 el primer manuscrito del Diyenís, el de Trebizonda,, descubierto en 1868 en esa ciudad del Mar Negro, en el monasterio de la Virgen de Sumelá, los estudiosos coincidieron en calificar a ese texto de "epopeya" o "poema épico". Así, lo hicieron Legrand, Sathas y Miliarakis. La primera edición y traducción del manuscrito de Trebizonda, en 1875, fue titulada por Sathas y Legrand Les exploits de Basile Digénis Acritas, épopée byzantine du dixième siècle. Posteriormente, Grégoire lo estudió siempre como "poema heroico"7 y Vasiliev no sólo lo menciona como "epopeya", sino que anota sus semejanzas con la Chanson de Roland y con el Poema del Cid".

Runciman también lo considera un poema épico y lo elogia en términos que hoy, en el estado del estudio de la épica medieval griega y con los criterios actuales, resultan absolutamente exagerados: "En algún período del siglo X apareció, escrito en verso político, un largo y popular poema épico en diez libros, contando la vida de un guerrero de la frontera oriental: Diyenís Akritas. Ha sido comparado con la Chanson de Roland. El poema occidental es quizás más dramático, pero en cuanto a la brillantez en las descripciones y a la delicadez psicológica, Diyenis Akritas es, con una diferencia infinita, muy superior, y puede reclamar para sí el puesto de la chanson de geste más espléndida que se haya escrito nunca"".

Quien primero utilizó el término "novela" fue Lambros, en su Collection de romans grecs en langue vulgaire et en vers, 1880. Pero se estaba refiriendo a una refundición erudita en la cual eran fuertes los elementos novelescos. La palabra "novela" fue repetida por Hesseling en 1911, al publicar por primera vez el texto E: Le roman de Digénis Akritas d'après le manuscrit de Madrid ${ }^{10}$. Si Lambros tenía cierta razón, pues publicaba una refundición erudita, no la tenía Hesseling, quien precisamente estaba dando a la luz el texto original o el más cercano al poema épico original, descubierto por Krumbacher y del cual el gran bizantinista publicó 300 versos en 1903.

La afirmación de Mavrogordatos de que tanto el héroe como la ambientación serían sólo simbólicos y de que no habría tras la narración

${ }^{6}$ J. Valero, op. cit., 58 y 60.

${ }^{7}$ H. Grégoire: Autour de l'épopée byzantine, Variorum Reprints, Londres 1975.

${ }^{8}$ A. A. Vasiliev: Historia del Imperio Bizantino, I, 449-452.

${ }^{9}$ S. Runciman: La civilización bizantina, 232.

${ }^{10}$ Publicado en el número 3 de la revista Laografía, 1911 (Atenas), pp. 555-604. 
hechos históricos, podría ser válida referida sólo a Grottaferrata y si no existiera Escorial. En éste no encontramos una serie de elementos novelescos que se dan en $\mathrm{G}$, mientras que otros se presentan muy abreviados; y - lo que es muy importante - E contiene un gran número de nombres de personajes que existieron, de toponímicos, de términos militares de la época, elementos de color local, todos los cuales no existen en $\mathrm{G}$ y en las otras versiones eruditas o están en ellas alterados o atenuados. Todos esos elementos configuran un escenario histórico y geográfico determinado o determinable. Alexíu ha expuesto detallada y fundadamente ese panorama en la "Introducción" a su edición crítica de 1988 y en su estudio "Elementos históricos y geográficos en Diyenís Akritas", 1991. Y, como ha observado Ricks $^{11}$, incluso elementos que pueden parecer extraños para la mentalidad occidental, como la intervención de la amazona Maximú y sus duelos con Diyenís, poseen un sabor oriental y no son ajenos a tradiciones y viejos mitos populares de carácter heroico de las regiones del Ponto y de Capadocia ${ }^{12}$, con probable raíz en la mitología antigua, en la creencia que menciona Heródoto ${ }^{13}$.

En E, resulta claro que es en la primera sección, en el Cantar del Emir, en la que la relación de los hechos con un tiempo y lugar históricos es más clara y llega a aproximarse a la fidelidad que ostenta el Poema del $\mathrm{Cid}^{14}$. En los otros cantares, hay algunos vestigios de elementos históricos, menos que en el primer cantar. La ambientación geográfica sigue siendo realista. Pero aunque los hechos narrados sean fantásticos, o puedan serlo en buena proporción, en todo caso, todos constituyen vestigios de un hecho real: la existencia de un héroe cuyas hazañas tuvieron una muy vasta resonancia a través de siglos, y cuyos ecos se perpetuaron no sólo en muchos territorios griegos a través de poemas populares breves, sino también en el ámbito eslavo.

Aunque pueda discutirse si se puede hablar de que existiera un «sentimiento nacional» en las hazañas del Cid y de Diyenís - y si era posible que hubiera sentimiento nacional en los cristianos de España y los de la Romanía $^{15}$, es claro que en el caso de los griegos, núcleo étnico principal

${ }^{11}$ D. Ricks: Byzantine Heroic Poetry, Bristol 1990. Ver bibliografía.

${ }^{12}$ D. Ricks, op. cit., 11.

${ }^{13}$ Heródoto: Historias, IV, 114.

${ }^{14}$ D. Ricks, op. cit., 13. Igualmente, citado por él: G. Huxley: "Antecedents and Context of Digenes Akrites", Greek Roman and Byzantine Studies, 15-111974, 317 327.

${ }^{15}$ C. Smith, al hablar de la historicidad para él presunta, del Poema del Cid y otras obras de la épica hispánica, pone en duda esa posibilidad. Op. cit. , 25 y s. 
dentro de lo que llamamos Imperio Bizantino, desde el siglo $\mathrm{X}$ comienza a dibujarse una conciencia distinta, como puede apreciarse en Constantino Paleólogo y en Plethón. La caída de Constantinopla y la consiguiente dominación otomana sobre los territorios helénicos postergó por siglos el nacimiento de un Estado moderno de los griegos. Pero los cantos sobre Diyenís sobrevivieron y se transmitieron de generación en generación hasta el mismo siglo XX. Tanto en la poesía popular, obra de cantores no letrados, anónimos, como en el recuerdo de la minoría letrada, sobrevivió la memoria de Diyenís asociada al anhelo de la liberación del dominio extranjero.

Beck ve en E dos partes, la primera de las cuales, el Cantar del Emir con claros caracteres épicos, y el resto es - en sus palabras - "lo que podríamos caracterizar como la Novela de Digenís" ${ }^{\prime 16}$. La posición de Beaton muestra, igualmente, las dificultades de una identificación del género que encuentran no pocos estudiosos. Desde ya califica el Diyenís E de "'epic' or proto-romance". Por una parte ve el Diyenís algunas características semejantes a las que se suelen señalar entre tres "poemas épicos" occidentales: La Chanson de Roland, el Poema de Mío Cid y el Nibelungenlied. Los cuatro «tratan el conflicto entre cristianos e infieles; están entre los más avanzados ejemplos de afianzada narrativa de las lenguas vernáculas que emergen en Europa; inauguran un nuevo género literario sin precedentes en la Edad Media; narran las hazañas de un grupo de personajes masculinos, de los cuales uno - Rolando, Rodrigo, Sigfrido, Diyenís - es presentado como preeminente; están construidos de acuerdo al principio de la estructura tripartita, en la cual la primera parte no está sólidamente enlazada con la segunda». Tales son los planteamientos de este estudioso respecto de las semejanzas entre los cuatro poemas. Parecen bastante válidos respecto de un Diyenís "epic". Pero éste sería, al mismo tiempo, el precursor de la novela griega que se desarrollará en el siglo XII en lengua $\operatorname{arcaizante}^{17}$, y que alcanzará después, en los siglos XIV y XV en la dimodis glosa, la lengua hablada, el neogriego. No deja de reconocer Beaton que no se observa en Diyenís conocimiento de la literatura universal, como se la halla en algún grado en todas las novelas griegas a partir de Ismini e Isminías en adelante. En cuanto a las semejanzas que claramente pueden hallarse entre el Diyenís y el Poema del Cid, ello obviamente no tiene relación con posibles influencias,

${ }^{16}$ H-G Beck: Historia de la literatura bizantina popular, Traducción al griego N. Eidenenier, Atenas 1988.

${ }^{17}$ Parece bien difícil pensar que el Diyenís E pudiera ser precursor de la novela bizantina erudita del siglo XII. 
sino con el hecho de que ambas epopeyas nacieron en un escenario histórico semejante, en lugares fronterizos entre el mundo cristiano y el musulmán, en el que estos mundos viven, conviven y luchan entre ellos.

Pero la diferencia más importante entre el Diyenís y las novelas griegas - tanto las de la Segunda Sofística, como las bizantinas del siglo XII, en lengua arcaizante, y las escritas en lengua dimodis en los siglos XIV y XV (y que consideramos neohelénicas), está en la estructura narrativa. La de las novelas es completamente distinta de la del Diyenís. En las novelas se da siempre una serie de episodios de desventuras y peripecias que pasan dos amantes, serie que llega a su fin con la unión, la tranquilidad y felicidad para siempre de la pareja. Faltan en las novelas la oposición entre pueblos y el consiguiente clima de lucha armada y la determinación del escenario histórico y geográfico en que se desarrollan las acciones.

Fenik en su libro Digenis Epic and popular Style in the Escorial Version ha estudiado detalladamente la organización de las descripciones, escenas y discursos en el Diyenís $E$, y para él el carácter épico del poema queda perfectamente claro; el texto posee todas las características básica de un estilo narrativo oral y "se nutre de una tradición viviente de poesía heroica"18. Este autor no sólo estudia similitudes del poema neogriego con epopeyas modernas, como la Chanson de Roland y los Nibelungos, sino también con los poemas homéricos. Para Fenik es claro que la composición del Diyenís E está organizada metódicamente sobre la base de ciertos patrones, como repeticiones, variaciones y desarrollos de temas, que son característicos de otras epopeyas; procedimientos composicionales que están todos enraizados en la poesía heroica tradicional, oral, a la que pertenecía o de la cual estaba muy cerca el autor de E. Es la tradición a la cual pertenecen sin duda el Cantar de Armuris y el Cantar del hijo de Andrónico en su forma original. Esto también parece claro a Michael y Elizabeth Jeffreys: el Diyenís Escorial está dentro de una larga tradición oral bizantina, cuyas trazas visibles emergen para nosotros en el siglo IX-X. Han estudiado especialmente el tema de esa tradición y han llegado a esa conclusión. La realidad es que, como Beaton lo ha demostrado ${ }^{19}$, el Akritas del Escorial está organizado alrededor de temas que se encuentran en una variedad de poemas populares breves («cantos populares griegos», dimotiká tragudia) neogriegos y de que la presencia de

${ }_{18}$ B. Fenik: Digenis Epic and popular Style in the Escorial Version, pp. 15 - 19.

19 R. Beaton: "Digenes Akritas and Modern Greek Folk Song A Reassesment", Byzantion 5-1961, 22-43. 
esos motivos muestra familiaridad, indica que "el poeta trabajaba dentro o muy próximo a una tradición dada" ${ }^{20}$.

Trapp, el editor de la hipotética versión Z, que habría sido una compilación de textos procedentes de Escorial y Grottaferrata y de la cual habrían derivado las versiones posteriores, desarrolla una argumentación convincente en pro del carácter épico de Diyenís E. Es claro para este estudioso que los elementos más novelescos o acaso mejor dicho menos heroicos de la historia de Diyenís, como el aspecto erótico muy desarrollado, el abundante detalle en las descripciones, los hallamos en los textos de Grottaferrata y de Trebizonda, y, en cambio, o no existen o se dan en menor proporción o atenuados en el texto E. Esto coincide con el carácter de esos textos, producidos por eruditos o personas que pretendían ser tales o escribir como tales, en una lengua arcaizante (aunque no sin mezcla con otro nivel de lenguaje); Y son posteriores el texto Escorial. Y por ser sus autores personas letradas, eruitas o semieruditas, pudieron recibir alguna influencia de la novela de la Segunda Sofística y de la novela bizantina del siglo XII, escrita en lengua arcaizante. En contraste con esa realidad, Trap destaca el hecho de no pocos de los caracteres de la poesía heroica se encuentran, sin duda, en el Diyenís E: el combate, la caza, la mujer guerrera, el rapto de mujeres, el rápido crecimiento del héroe ${ }^{21}$. A ello naturalmente hay que agregar el valor de la valentía y fuerza como cualidades principales del héroe y la conciencia que éste posee de estar dotado con esos dones.

El profesor Stilianós Alexíu, quien realizó las ediciones críticas del Diyenís E y de los Cantares de Armuris y del Hijo de Andrónico y ha dedicado una serie de estudios a estos textos, no tiene dudas en considerar una epopeya al Diyenís E. Es fundamental para él la existencia en este texto de la relación de la trama con acontecimientos y personajes históricos y tradiciones sobre las hazañas guerreras de éstos, así también la relación del relato con un ciclo de cantares heroicos anteriores. De tales cantares, la epopeya extrae su materia principal y, asimismo, recursos expresivos propios de la poesía oral: motivos típicos, escenas típicas, fórmulas, versos repetidos, repetición de escenas. Es evidente que la dicción y versificación del Diyenís y los dos cantares breves dejan ver un sistema formulario, es decir, una base de expresiones estereotipadas, tradicionales, no pocas de las cuales se siguen

${ }^{20}$ B. Fenik, op. cit., 15.

${ }^{21}$ E. Trapp: «Digenes Akritas, Epos oder Roman», en Studi Classici in onore di Quintino Cataudella, 2, Catania 1972, cit. Por Alexíu 1985, 68. 
hallando en la poesía popular posterior, en los llamados «cantos populares», dimotiká tragedia.

Como el Diyenís E es un poema no muy extenso - 1867 no se puede esperar hallar un gran número de combates. Pero los hay no sólo en la realidad de la narración, sino también en el recuerdo que los personajes hacen de enfrentamientos con enemigos, apelates o ejércitos árabes. Tanto el padre del héroe, el emir Musuros en el primer cantar, como Diyenís a partir del segundo, recuerdan hazañas guerreras y se glorían de ellas. En ellas han demostrado coraje sin límites y han utilizado las armas típicas de la época, la maza, la espada y la lanza. Esas descripciones hechas por los personajes y las que hace el poeta responden a la necesidad de representación de la violencia guerrera que tiene el auditorio de la poesía heroica. Bowra observa que estos auditores reciben a menudo la narración heroica como «a record of fact». Trap, por su parte, anota que cuando el autor de los Poemas Ftojoprodrómicos ${ }^{22}$ llama al emperador Manuel Comnenos «el potente guerrero, el nuevo Akritas», evidentemente alude a Diyenís como una figura heroica conocida, concreta y ejemplar en su época, y no a un personaje de una novela.

La ejemplaridad de la figura del personaje es un elemento propio de la epopeya, una característica que diferencia el relato heroico del relato novelesco. En las expresiones del poeta y en las de los otros personajes cuando se refieren al Cid y a Diyenís, percibimos que el cantor popular expresa una profunda admiración por ellos, y al cantar sus hechos interpreta el sentimiento colectivo de admiración por esos personajes, un sentimiento colectivo de identificación con el carácter paradigmático. Esta ejemplaridad es destacada por Daniel Poirion entre las funciones de la epopeya románica señaladas por Joseph Duggan: "Todas estas funciones se resumen en la fabricación de modelos, de ejemplos a partir a partir de personajes históricos sobre los que se cuentan anécdotas más o menos legendarias"23.

${ }^{22}$ El texto y la traducción castellana de estos poemas realizada por el profesor Egea, en Versos del gramático señor Teodoro Pródromo el Pobre o Poema Ptocoprodrómicos. Editados por J. M. Egea. Centro de Estudios Bizantinos, Neogriegos y Chipriotas, Universidad de Granada, Granada 2001.

${ }^{23}$ J. J. Duggan: The Song of Roland Formulaic Style and Poetic Craft, Universidad de California 1973, cit. por Jesús Montoya: «Un testimonio español de lectura y de audición de épica", 104: Duggan señala cinco posibles funciones de la epopeya románica: la diversión, la sanción, la información, la memoria y el ejemplo. Esta última es la que destaca Daniel Poirion: Précis de littérature française du Moyen 
Tanto en el Poema de Mío Cid como en el Diyenis Akritas, es claro que el elemento central es la existencia de un héroe y el relato de sus hazañas. La definición de Max Scheler caracteriza al héroe, expresando que él «es la personificación de lo noble, es decir, la suma de todas las excelencias y virtudes, no solamente espirituales, sino vital-espirituales" ${ }^{24}$. La valentía, la audacia, la intrepidez, la fortaleza, la nobleza; el sentido de honor, de la lealtad y de la gloria, se reflejan en los hechos - y también en las palabras del héroe. A través de sus actos, el héroe da corporeidad a sentimientos, esperanzas, ideales de una comunidad, de un pueblo. En el Cid y en el Diyenís se dan estas características las que se muestran en acciones que tienen lugar en un escenario semejante: la frontera entre el mundo cristiano y el musulmán, ámbito en que se dan circunstancias parecidas. Las observaciones de T. Papadopoullos sobre el héroe de zonas fronterizas son válidas tanto para el Cid como para Diyenís ${ }^{25}$.

Y no sólo la existencia en el poema de un héroe y el relato de sus hazañas, caracterizadas por el coraje con que son cumplidas, son lo que dan carácter épico, heroico, a una obra. Es también importante la posición del poeta, la actitud del poeta ante esa materia: hombre y proezas. Como expresa Oscar Gerardo Ramos, el poeta «es quien fundamentalmente determina la ontología de la epopeya. Respecto a la narración que hace, a los personajes que crea y a las audiencias a las cuales se dirige, el rapsodo se coloca a una distancia lejana, impersonal y magnificada; esta actitud así contemplada, es la supraperspectiva y ella configura en parte primordial la ontología de la epopeya $^{26 \%}$. Para Ramos, esa distancia, ese distanciamiento proviene principalmente de dos realidades. Por una parte, el poeta quiere cantar lo que la comunidad quiere que cante, quiere cantar a un personaje admirado por esa comunidad como excepcional por su valor y otras virtudes asociadas a la valentía y el coraje. De otro lado, el tiempo transcurrido entre los hechos heroicos y el momento en que son cantados, tiempo que puede ser bastante largo (pero también a veces relativamente breve), ha producido un

Age, París 1963, 65, cit. por J. Montoya, op. cit., 104. El estudio de Montoya en Memorias de la Real Academia de Buenas Letras de Barcelona, XXII, 1990, 97 y s.

${ }^{24}$ M. Scheler: El santo, el genio, el héroe, Editorial Nova, Buenos Aires 1961, 95. Para él, "audacia, valentía, intrepidez, presencia de énimo, amor a la lucha, arrojo, riesgo", son cualidades del héroe.

${ }^{25}$ T. Papadopoullos: The Akritic Hero: Socio-Cultural Status in the Light of Comparativa Data, 1993.

26 O. G. Ramos: Categorías de la epopeya, Instituto Caro y Cuervo, Bogotá 1988, 13. Los destacados son del original. 
depuramiento, una especie de cristalización de aquellas acciones admirables. Los elementos esenciales de aquellas acciones y aquellos acontecimientos se han fijado y se han instalado en el sentir de la comunidad y, por lo tanto, en el del poeta inmerso en esa sociedad.

Pensamos con los estudiosos que hemos citado que el carácter heroico del Poema de Diyenís y del Poema de Mío Cid es innegable. Pero también es claro que en ambos encontramos elementos novelescos. Esto no va en desmedro de la epicidad de estas obras. Si echamos una mirada a otras epopeyas no eruditas, en todas, en mayor o menor proporción, se advertirá la presencia de elementos propios de la novela y del cuento. Acaso es la Ilíada la epopeya que menos elementos novelescos presenta. En la Odisea, ellos son claros y abundantes. Sin embargo, tradicionalmente se la considera un poema épico. El combate no sólo está presente en ella a través de los recuerdos que hacen los personajes de los hechos de Troya, sino también en las acciones del mismo Odiseo durante el viaje de retorno a su patria después del fin de la guerra.

En los Nibelungos, los elementos novelescos son claros, junto a algunos en los que resulta nítida la cercanía con el cuento popular. No por ello .le negaríamos el carácter épico.

El estudio de George Tyler Northup plantea desde su título no la duda sino la convicción de que el Poema de Mío Cid no es epopeya: El poema del Cid visto como una novela. Varios otros estudiosos han formulado el mismo cuestionamiento, entre ellos Kienast, Dorfman y Curtius. Northup no acepta el carácter histórico y nacional del Poema del $\mathrm{Cid}^{27}$. Spitzer ve en las bodas de las hijas del Cid y en sus consecuencias el núcleo de la obra. La toma de Valencia, la mayor proeza del héroe mereció pocos versos del juglar. También pone en duda la historicidad del asunto. Dorfman no considera importante del Cantar Primero, sino que ve en él una introducción o prólogo a la verdadera materia del poema, que serían las bodas de las hijas. Se han empleado para calificar al Poema del Cid términos muy semejantes a los que encontramos en los detractores del carácter épico del Diyenís. Spitzer habla de «biografía novelizada o epopeyizada». Para Singleton, el poema constituye una combinación de epopeya y novela ${ }^{28}$.

${ }^{27}$ G.Tyler Northup: «The Poema of the Cid viewed as a Novel», Philological Quarterly, XXI, 1942, 8.

${ }^{28}$ M. Singleton: «The Two Techniques in the Poema de Mío Cid", RP V, 1951-1952, 222-227, cit. por De Chasca: Estructura y forma en el Poema de Mío Cid, 21. 
Más allá de los elementos novelescos que se encuentran en el Poema de Mío Cid y en la Epopeya de Diyenís Akritas, el carácter épico de ambos textos es indudable. Esto asemeja ambas obras. Las figuras de ambos héroes están igualmente cerca en ciertos aspectos, mientras en otros existen diferencias notables. Hay que tomar en cuenta que el Cid es un personaje épico de especiales características si se piensa en otras epopeyas: no es un joven impulsivo y temerario, sino un hombre de mediana edad en cuyo ánimo predominan la mesura y la serenidad. Por el contrario, Diyenís es joven y temerario y muere joven. En la muerte de ambos sí hay similitud. No mueren en una batalla, sino de enfermedad. A la muerte del Cid, el poeta dedica un verso y medio, pues el siguiente verso es una reflexión sobre el destino común de los humanos:

Passado es deste sieglo el día de çinquaesma: ¡de Christus haya perdón!

¡Assí ffagamos nos todos, justos e peccadores!

El poema griego dedica, en cambio, 91 versos a los momentos finales de Diyenís. Y si, como lo hace Alexíu, no se considera auténtico el pasaje siguiente, la muerte misma del héroe no estaría contada dentro del poema. Los 71 versos finales, relegados por Alexíu a un anexo, sí narran brevemente la muerte de Diyenís y la de su esposa. La mayor parte de esta sección, 53 versos - v. 1807 al 1860 - la ocupa la plegaria de la esposa de Diyenís, oración que se asemeja bastante a la de doña Jimena en San Pero de Cardeña, en las momentos que preceden a la partida del Cid al destierro, v. 330 al $365^{29}$.

Si bien Diyenís es joven y temerario, muestra a la vez mesura, como el Cid. Es más, podríamos decir que hallamos cierto ascetismo en ambos héroes. Es verdad que el Cid muestra el afán de honores y de riquezas más acentuadamente que Diyenís. Pero ni este anhelo ni el deseo de gloria ostenta en ambos el grado que se observa en otros héroes. En este sentido, podemos también caracterizar ambos poemas y ambos héroes por un sentido de mesura que no hallamos en la Chanson de Roland ni en los Nibelungos. Y aunque las semejanzas entre el Cid y Diyenís no constituyen el tema de este artículo,

${ }^{29}$ Respecto de la oración de la esposa de Diyenís, casi podríamos repetir el juicio de Colin Smith: «La conmovedora plegaria de Jimena recoge todos los ejemplos de asistencia divina en favor del hombre doliente que ella puede reunir, con la creencia de que Dios ayudará también al Cid en la hora de necesidad”. C. Smith, op. cit. 280. 
salvo en cuanto tienen relación con el carácter épico de los poemas que los cantan, recordamos que ambos mueren "de muerte natural" y no en combate. Sigfrido cae víctima de una traición y Rolando en medio del fragor de una terrible batalla.

Creemos que así como en la realidad no se encuentran en forma «pura» en las obras literarias las características que tradicionalmente se han señalado para cada género, igualmente no hallamos en forma estricta en los héroes todas las cualidades que se les han atribuido ni en el mismo grado en unos y otros.

Referencias bibliográficas

Textos

«Le roman de Digénis Akritas d'après le manuscrit de Madrid » par D. C.

Hesseling, Laografía 3-1911 (Atenas).

Vasilios Diyenís Akritas Epopiía vizandiní tis 10is ekatontaetiri/dos katá to

en Andro enafrethén jirógrafon, hipó And. Miliaraki, 1881. Reed. P.

G. Zerlendis, Atenas 1920.

I deka lo/yi tou Diyenoús Akritou Pezí diaskeví ekdidomeni hipó Dim Pasjalis

Laografía 9-1928 (Atenas).

Vasilios Diyenís Akritas Ta émetra kímera Athinwn... Kriptoferris ke

Escorial. Ed. Kalonaros 1941, xanatípwsi Ed. D. Papadimas, Atenas

1970. Contiene también traducciones de las versiones rusas.)

Digenes Akrites. Edited with Introduction, Translation and Commentary by

John Mavrogordato, Oxfrod 1956. (Reproduce y traduce texto G.)

Digenes Akrites: Synoptische Ausgabe der ältesten Versionesn. Ed. de E.

Trapp. Viena 1971. (Contiene textos E, G y Z.)

Basilio Digenis Akritas (texto G). Introducción, cronología, bibliografía y notas y traducción inédita Juan Valero G., Bosch Ed.. Barcelona 1985.

Vasilios Diyenís Akritis (katá to jirógrafo tou Escorial ke to Ásma tou Armouri. Kritikí ékdosi, isagwyí, simi'wsis, glwsario Stilianós Alexíu. Hermís, Athena 1985.

Vasilios Diyenís Akritis ke ta Ásmata tou Armouri ke tou Ioú tou Andrónikou Epimelia Stilianós Alexíu. Hermías, Atenas 1990.

Byzantine Heroic Poetry. Ed. de David Ricks de Diyenís E y del Cantar de

Armuris, con traducción inglesa, según textos de St. Alexíu con

algunas variantes. Bristol Classical Press, Bristol 1990.

Poesía heroica griega Epopeya de Diyenís Akritas Cantares de Armuris y de 
Andrónico. Reproduce edición crítica de St. Stilianós, con traducción métrica, estudio, notas y bibliografía de M. Castillo Didier. Centro de Estudios Griegos, Bizantinos y Neohelénicos de la Universidad de Chile, Santiago 1994.

Estudios

Ahreweiler, H. 1974.'La frontière et les frontières de Byzance en Orient", Actes du XIVe Congrès Internationel des Études Byzantines [1972]. Bucarest.

Allen, L. H. 1959. "A structural analysis of the epic style of the Cid", Structural Studies on Spanish Themes, Acta Salmaticensia XII No 3. Salamanca.

Alexíu, St. 1993. "Escorial or Grottaferrata? An overview", en Beaton, R. \& Ricks, D. (Edit.): Digenis Akrites New Approaches to byzantine Heroic Poetry. Londres: Variorum Reprints.

Alexi/u, St. 1993. "Historiká ke yeografiká ston Diyení Akriti, en Efróninon Homenaje a M. Jatzidakis. Atenas.Alexiu, St. 1985. "Isagoyi", en Vasilios Diyenís Akritis ke to Asma tou , Armouri, edición crítica. Atenas: Hermís.

Alexíu, St. 190. "Isagoyí”, en Vasilios Diyenís Akritis ke ta Ásmata tou Armouri ke tou Hiyoú tou Andrónikou.Atenas: Hermís.

Alvar, M. 1986. Cantares de gesta medievales. México: Porrúa. Andrónikos, M. 1969. "To palati tou Diyení Akrita”, en Epistimonikí Epetirís Filosofikís Sjolís Panepistimíou Thesalonikis XI. Tesalónica:

Universidad de Tesalónica.

Anónimo 1908. Cantar de Mío Cid. Texto, gramática y vocabulario por R.

Menéndez Pidal. Madrid: Espasa Calpe.

Anónimo 1991. Poema de Mío Cid. Edición de Colin Smith. Madrid:

Cátedra.

Beaton, R. 1993. "An epic in the making? The early version of Digenes Akrites", en Beaton, R. \& Ricks, D. New Approaches to Byzantine Heroic Poetry.

Beaton, R. 1980. Folk Poetry of Modern Greece.Cambridge: Cambridge University Press.

Beaton, R. 1989. The Medieval Greek Romance. Cambridge: Cambridge University Press.

Beck, H.-G. 1972. "Formprobleme des Akritas-Epos", en Ideen und Realitaeten in Byzanz. Londres: Variorum Reprints.

Beck, H.-G. 1988. Historía tis dimodous byzantinís logotejnías. Trad. Al griego N. Eideneir. Atenas XXXXXX 
Bryer, A.- 1993. “The historians'sDigenes Akrites”, en Digenes Akrites New Aproaches.

Castillo Didier, M. 1966. "Poesía popular neogriega”. Separata de Anales de la Universidad de Chile. Santiago: Editorial Universitaria.

Castillo Didier, M. 1997.“Stojasmí gia mia singritikí meleti metaxí tou Epous Diyení E ke tou piímatos tou Cid", en Actas del IV Congreso de Literatura Comparada. Atenas.

Castillo Didier, M. 1989. "To Épos tou Diyení ke to Píima tou Cid”, en Ariadni 5. Réthimno: Universidad de Creta.

Castillo Didier, M. 1997. «El Poema de Mío Cid y la Epopeya de Diyenís Akritas», Actas del I Congreso de Nehelenistas de España e Iberoamérica. Granada: Athos-Pérgamos Universidad de Granada.

Eidenier, N. 1970. "Diorthotiká sto kímeno tou Diyení tis Kriptoferris" Heliniká 23. Tesalónica: Hetería Makedonikón Spoudón.

Fenik, B. 1991. Digenis Epic and Popular Style in the Escorial Version Heraklion: Universidad de Creta.

Fenik, B.: "The narrative style in the Escorial Digenis Akritis", en Ariadni 5. Réthimno: Universidad de Creta.

Grégoire, H. 1975. Autour de l'epopée byzantine. Londres: Variorum Reprints.

Hesseling, D. C. 1911. "Introduction" a Le roman de Digénis Akritas d'après de Madrid. Ver Textos.

Hook, D. 1993. "Digenes Akrites and the Old Spanish Epics", en New Approaches...

Jeffreys, E. 1983. "Digenis Akritas Manuscript Z”, en Dodoni IV. Ioanina: Universidad de Ioanina.

Jeffreys, E. 1993. "The Grottaferrata versión of Digenis Akrites: a reasessment", en New Approaches...

Jeffreys, M. and E.1983. Popular Literature in Late Byzantium. Londres: Variorum Reprints.

Krumbacher, K. 1955. Geschichte der Byzantinischen Literatur, trad. al griego G. Sotiriadis. Atenas: Pápiros.

Lavagnini, R. 1993. «Il poeta del Dighenis Akritis», en Panayotakis, N.: Los comienzos...

Lord, A. B. 1980. «Tradition and innovation in Balkan epic. From Heracles and Theseus to Digenis Akritas and Marko», en Revue des Études Sud-Est Europénnes XVIII, 2.

Magdalino, P. 1989. «Honour among Romaioi: the frame work of social values in the world of Digenes Akrites and Kekaumenos», en 
Byzantine and Modern Greek Studies 13. Birmingham.

Martino, A. B. 1986. «Mío Cid y Dighenis Akritas en la tradición juglaresca

(Aportes para una comparación)», en La juglaresca Actas del I

Congreso Internacional sobre la Juglaresca. Madrid: EDI-6 S. A.

Mavrogordato, J. 1956. «Introduction» a Digenes Akrites Edited with an

Introduction, Translation and Commentary by J. M. Oxford.

Menéndez Pidal, R. 1973. El Cid Campeador, 7a. ed. Madrid: Espasa-Calpe.

Menéndez Pidal, R. 1947. La España del Cid, 4a. ed. Madrid: Espasa-Calpe.

Notopoulos, J. 1959. «Originality in Homeric and Akritan formulae», en

Laografía 18. Atenas.

Obolensky, N. 1974. «Byzanrine frontier zones and cultural exchanges», en

Actes du XIVe Congrès Internationel des Études Byzantines.

Bucarest.

Pertusi, A. 1970. «La poesia epica bizantina e la sua formazione: problemi sul fondo storico del 'Digenis Akritas'», en Atti del Convegno

Internazionale sul tema La poesia epica e la sua formazion. Roma.

Politis, L. 1975. «L'Épopée byzantine de Digénis Akritas. Problèmes de la

tradition du texte et des rapport avec les chansons akritiques», en

Paléographie et littérature byzantine et néogrecque. Londres:

Variorum Reprints.

Prombonás, I. 1987. Akritiká Estudios akríticos I. Atenas.

Ramos, O. G. 1988. Categorías de la epopeya. Bogotá: Instituto Caro y Cuervo.

Ricks, D. 1990. Byzantne Heroic Poetry. Bristol: Bristol Classical Press.

Ricks, D. and Beaton, R. (Edits.) 1983. Digenes Akrites New Approaches to Byzantine Heroic Poetry. Londres: Variorum Reprints.

Runciman, St. 1942. La civilización bizantina, trad. A. J. Dorta. Madrid: Ed. Pegaso.

Scheler, M. 1961. El santo, el genio, el héroe. Buenos Aires: Editorial Nova.

Sifakis, G. M. 1988. Gia mia piitikí tou Diyení E ke ton akritikón tragoudión. Hiraklio: Universidad de Creta.

Smith, C. 1991. «Introducción» a Poema de Mío Cid Edición de Colin Smith. Madrid: Cátedra.

Trapp., E. 1971. Digenes Akritas. ver: Textos.

Vasiliev, A. A. 1946. Historia del Imperio Bizantino, Trad. J. G. de Luaces Barcelona: Joaquín Gil Ed.

Valero, J. 1985. «Introducción» a Vasilios Digenís Akritas. Introducción, cronología, bibliografía, notas y traducción inédita de J. V. Barcelona: Bosch. 